\title{
Immunolocalization of leptin and its receptor in the sheep ovary and in vitro effect of leptin on follicular development and oocyte maturation
}

\author{
Taís Jobard S. Macedo ${ }^{\mathrm{a}}$, Jamile Maiara S. Santos ${ }^{\mathrm{a}}$, Maria Éllida S. Bezerra ${ }^{\mathrm{a}}$, Vanúzia G. Menezes ${ }^{\mathrm{a}}$, \\ Bruna B. Gouveia ${ }^{a}$, Lara Mariane R. Barbosa ${ }^{a}$, Thae Lane Barbosa G. Lins ${ }^{\mathrm{a}}$, Alane Pains O. Monte ${ }^{\mathrm{a}}$, \\ Ricássio S. Barberino ${ }^{\mathrm{a}}$, André M. Batista ${ }^{\mathrm{b}}$, Vanessa Raquel P. Barros ${ }^{\mathrm{a}}$, Aurea Wischral ${ }^{\mathrm{b}}$, \\ Mário Adriano A. Queiroz ${ }^{c}$, Gherman Garcia L. Araújo d, Maria Helena T. Matos ${ }^{\mathrm{a},}$ \\ ${ }^{a}$ Nucleus of Biotechnology Applied to Ovarian Follicle Development, Federal University of São Francisco Valley, Petrolina, PE, Brazil \\ ${ }^{\mathrm{b}}$ Laboratory of Animal Reproduction, Federal Rural University of Pernambuco, Recife, PE, Brazil \\ ${ }^{\mathrm{c}}$ Laboratory of Bromatology and Animal Nutrition, Federal University of São Francisco Valley, Petrolina, PE, Brazil \\ ${ }^{\mathrm{d}}$ Embrapa Semi-Arid, Petrolina, PE, Brazil
}

\section{A R T I C L E I N F O}

\section{Keywords:}

Follicular development

Immunohistochemistry

Oocyte

Ovary

Sheep

\begin{abstract}
A B S T R A C T
The aims of the study were to characterize leptin and it is receptor (LEPR) proteins immunoexpression in ovine ovaries and to evaluate the effects of leptin on development of secondary follicles cultured in vitro. The ovaries were collected and fixed for immunohistochemical analysis. Additional pairs of ovaries were collected and secondary follicles were isolated and cultured, for 18 days, in $\alpha-\mathrm{MEM}^{+}$alone or supplemented with $10 \mathrm{or} 25 \mathrm{ng} /$ $\mathrm{mL}$ of leptin. The antrum formation and fully grown oocytes rates were higher in $25 \mathrm{ng} / \mathrm{mL}$ leptin than all treatments. GSH levels and mitochondrial activity were higher in 10 or $25 \mathrm{ng} / \mathrm{mL}$ leptin than $\alpha$-MEM ${ }^{+} .25 \mathrm{ng} /$ $\mathrm{mL}$ leptin showed a higher percentage of MII than the $\alpha-\mathrm{MEM}^{+}$. In conclusion, leptin and its receptor are expressed in ovine ovaries and $25 \mathrm{ng} / \mathrm{mL}$ leptin promoted higher in vitro maturation rates by improving follicular development, GSH levels and mitochondrial activity of ovine oocytes compared to control medium.
\end{abstract}

\section{Introduction}

The in vitro culture of isolated secondary follicles has been performed in sheep to obtain a larger number of meiotically competent oocytes (Kamalamma et al., 2016; Lunardi et al., 2016). However, the number of embryos produced from in vitro grown preantral follicles is very low (Arunakumari et al., 2010; Luz et al., 2012). One aspect that may be responsible is the generation of oxidative stress by the production of reactive oxygen species (ROS) under in vitro environmental conditions (Combelles et al., 2009; Yu et al., 2014). ROS can pass through cell membrane and induce numerous effects, including mitochondrial dysfunction (Guerin et al., 2001), which significantly decrease ATP synthesis in oocytes, resulting in decreased oocyte quality with adverse effects on maturation and fertilization (Van Blerkom, 2004; Ramalho-Santos et al., 2009; Chappel, 2013). As mitochondria are major sites of ROS production (Chen et al., 2003), maintenance of stable mitochondrial function in oocytes is important to prevent the direct production of ROS (Niu et al., 2017). Therefore, the use of substances with antioxidant properties during the in vitro culture of follicles may prevent mitochondrial dysfunction and oxidative damage or support the proper pro-/antioxidant balance by influencing, for example, intracellular glutathione (GSH) production, which protects oocytes against toxic injury due to oxidative stress (Ou et al., 2012).

Leptin, a 167-amino acid hormone (Zhang et al., 1994), is among the substances that have already demonstrated antioxidant activity (Bilbao et al., 2015) and beneficial action on follicular development, oocyte maturation and embryo production in vitro (Jin et al., 2009; Kamalamma et al., 2016; Keshrawani et al., 2016). Leptin is secreted mainly by adipocytes (Tsai et al., 2012) and is part of the adipokine family, which also includes resistin, adiponectin, visfatin, omentin and vaspin. It is involved in the regulation of food intake and energy homeostasis. Moreover, leptin is deeply involved in female reproductive system regulation by acting on the gonadotropic axis and on the ovaries (Catteau et al., 2015).

The hormone leptin exerts its biological effects by interacting with its receptor (LEPR) (Tartaglia et al., 1995). Expression of mRNA for

\footnotetext{
* Corresponding author. Universidade Federal do Vale do São Francisco (UNIVASF), Campus de Ciências Agrárias, Colegiado de Medicina Veterinária, Laboratório de Biologia Celular, Citologia e Histologia, Rodovia BR 407, Km 12, Lote 543 - Projeto de Irrigação Nilo Coelho - S/N, C1, CEP: 56300, Petrolina, PE, Brazil.

E-mail addresses: helena.matos@univasf.edu.br, htmatos@yahoo.com (M.H.T. Matos).
} 
leptin and LEPR have been reported in the oocyte, granulosa, cumulus and theca cells in antral follicles of different species (human: Cioffi et al., 1997; murine: Matsuoka et al., 1999; bovine: Paula-Lopes et al., 2007; caprine: Batista et al., 2013; ovine: Munõz-Gutiérrez et al., 2005; Taheri and Parham, 2016). In addition, the leptin and LEPR proteins have already been demonstrated in oocytes and granulosa cells from goat follicles at all stages of development (Batista et al., 2013).

Using the rat as a model, Bilbao et al. (2015) have demonstrated that a daily stimulus with low doses of leptin induces follicular growth, decreases ROS levels and Bax and active caspase- 3 expression. In vitro studies have reported that supplementation of the maturation medium with leptin improved the developmental capacity of the oocytes, increased blastocyst rates (bovine: Boelhauve et al., 2005; bubaline: Khaki et al., 2014; Sheykhani et al., 2016; Panda et al., 2017; swine: Craig et al., 2004), and reduced apoptotic cells (bovine: Boelhauve et al., 2005; bubaline: Panda et al., 2017). Moreover, addition of leptin to the culture medium of ovine isolated secondary follicles increased antrum formation and follicular growth as well as the percentage of oocytes in metaphase II (Kamalamma et al., 2016). However, the mechanisms underlying the actions of leptin on sheep ovarian follicle survival and growth have not yet been clearly understood. Therefore, it is still necessary to evaluate whether the main effect of leptin involves oxidative stress response through GSH production and/or mitochondrial activity in follicular cells. Furthermore, additional immunohistochemistry to detect leptin and LEPR proteins would be important to evaluate if leptin could be involved in the ovarian function in sheep.

Thus, the aims of this study were to 1) characterize protein expression for leptin and its receptor (LEPR) in ovine ovaries, and 2) to evaluate the effect of leptin addition to the base medium on the morphology (survival), growth, GSH and active mitochondria levels, as well as meiotic resumption of oocytes from ovine secondary follicles cultured in vitro.

\section{Material and methods}

Unless otherwise mentioned, all chemicals used in this study were purchased from Sigma Chemical Co. (St. Louis, MO, USA).

\subsection{Source of ovaries}

For immunohistochemical studies, ovarian cortical tissues $(n=10$ ovaries) were collected at a local abattoir from five adult (1-3 years old) non-pregnant mixed-breed sheep. The animals used in this study were non-pregnant and presumed to be undergoing normal oestrous cycles as judged by the presence of normal corpora lutea at slaughter. Immediately postmortem, the pairs of ovaries were washed once in $70 \%$ alcohol followed by twice washes in Minimum Essential Medium buffered with HEPES (MEM-HEPES) and antibiotics $(100 \mu \mathrm{g} / \mathrm{mL}$ penicillin and $100 \mu \mathrm{g} / \mathrm{mL}$ streptomycin). Thereafter, the ovaries were fixed in $10 \%$ buffered formalin (Dinâmica, São Paulo, Brazil). For in vitro culture, additional pairs of ovine ovaries ( $\mathrm{n}=50$ ovaries) were collected and transported within $1 \mathrm{~h}$ to the laboratory in tubes containing washing medium at $4{ }^{\circ} \mathrm{C}$ (Chaves et al., 2008).

\subsection{Immunohistochemistry evaluation of LEP and LEPR expression}

Immunohistochemistry was performed as described previously (Barberino et al., 2017). After $18 \mathrm{~h}$ of fixation, the ovarian tissue was dehydrated with increasing concentrations of ethanol (Dinâmica), clarified in xylene (Dinâmica), and embedded in paraffin (Dinâmica). Sections ( $5 \mu \mathrm{m}$ thick) from each block were cut using a microtome (EasyPath, São Paulo, Brazil) and mounted in Starfrost glass slides (Knittel, Braunschweig, Germany). Thereafter, the slides were incubated in citrate buffer ( $\mathrm{pH}$ 6.0) (Dinâmica) at $95^{\circ} \mathrm{C}$ in a decloaking chamber (Biocare, Concord, USA) for $40 \mathrm{~min}$ to retrieve antigenicity, and endogenous peroxidase activity was prevented by incubation with $3 \% \mathrm{H}_{2} \mathrm{O}_{2}$ (Dinâmica) and methyl ethanol (QEEL, São Paulo, Brazil) for $10 \mathrm{~min}$. Non specific binding sites were blocked using $1 \%$ normal goat serum (Biocare) in phosphate-buffered saline (PBS, pH 7,2). Subsequently, the sections were incubated in a humidified chamber for $90 \mathrm{~min}$ at room temperature with rabbit polyclonal anti-leptin [(H146): sc-9014] (1:40) and anti-LEPR [(H - 300): sc-8325] (1:100) (Santa Cruz Biotechnology, Santa Cruz, CA, USA). Thereafter, the sections were incubated for $30 \mathrm{~min}$ with MACH4 Universal HRP-polymer (Biocare). Protein localization was demonstrated with diaminobenzidine (DAB; Biocare), and the sections were counterstained with hematoxylin (Vetec, São Paulo, Brazil) for 1 min. Negative controls (reaction control) underwent all steps except the primary antibody incubation.

Preantral follicles were classified as defined previously (Santos et al., 2014) in primordial (oocyte surrounded by as single layer of squamous or squamous and cuboidal granulosa cells), primary (oocyte surrounded by a single layer of cuboidal granulosa cells) or secondary (oocyte surrounded by two or more layers of cuboidal granulosa cells). Antral follicles were classified as early ( $<3 \mathrm{~mm}$ presence of an antral cavity) or large (presence of a cavity filled with follicular liquid and well-developed theca layers). In the different follicular compartments (oocyte, and granulosa, cumulus, mural and theca cells), the immunostaining was classified as absent, weak, moderate or strong (Silva et al., 2004). The slides were examined using a light microscope (Nikon, Tokyo, Japan) at 100 and/or 400x magnification by two experienced researchers in a blinded manner to avoid variation.

\subsection{Isolation and selection of secondary follicles}

Isolation, selection, culture and follicular evaluation were performed according to Macedo et al. (2017). In the laboratory, the surrounding fatty tissues and ligaments were stripped from the pair of ovaries. Ovarian cortical slices (1-2 mm thick) were cut from the ovarian surface using a surgical blade under sterile conditions and subsequently placed in fragmentation medium consisting of MEMHEPES with antibiotics. Secondary follicles, approximately $240-270 \mu \mathrm{m}$ in diameter without antral cavities, were visualized under a stereomicroscope (Nikon) and mechanically isolated by microdissection using 26-gauge (26 G) needles. These follicles were then transferred to $100 \mu \mathrm{L}$ droplets containing base culture medium ( $\alpha$-MEM) for evaluation of quality. Follicles selected for in vitro culture had an intact basement membrane, two or more layers of granulosa cells and a visible and healthy oocyte that was round and centrally located within the follicle, without dark cytoplasm.

\subsection{In vitro culture of ovine secondary follicles}

After selection, isolated follicles were pooled and then randomly allocated to three treatments with approximately $45-50$ follicles per treatment. Follicles were individually cultured (one follicle per droplet) in $100 \mu \mathrm{L}$ droplets of culture medium under mineral oil in petri dishes $\left(60 \times 15 \mathrm{~mm}\right.$, Corning, Sarstedt, Newton, NC, USA) at $39^{\circ} \mathrm{C}$ under $5 \%$ $\mathrm{CO}_{2}$ for up to 18 days. The base control medium consisted of $\alpha$-MEM (pH 7.2-7.4) supplemented with $3.0 \mathrm{mg} / \mathrm{mL}$ bovine serum albumin (BSA), $10 \mathrm{ng} / \mathrm{mL}$ insulin, $5.5 \mu \mathrm{g} / \mathrm{mL}$ transferrin, $5.0 \mathrm{ng} / \mathrm{mL}$ selenium, $2 \mathrm{mM}$ glutamine, $2 \mathrm{mM}$ hypoxanthine and $50 \mu \mathrm{g} / \mathrm{mL}$ ascorbic acid, and then referred as $\alpha-\mathrm{MEM}^{+}$. For the experimental conditions, the control medium $\left(\alpha-\mathrm{MEM}^{+}\right)$was supplemented with 10 or $25 \mathrm{ng} / \mathrm{mL}$ human recombinant leptin (L4146; it has $92 \%$ molecular homology with ovine leptin). Every 2 days, $60 \mu \mathrm{L}$ of the culture media was replaced with fresh media in each droplet.

\subsection{Evaluation of follicle morphology and development}

Analysis of follicular morphology was performed every six days of culture using a pre-calibrated ocular micrometer in a stereomicroscope 

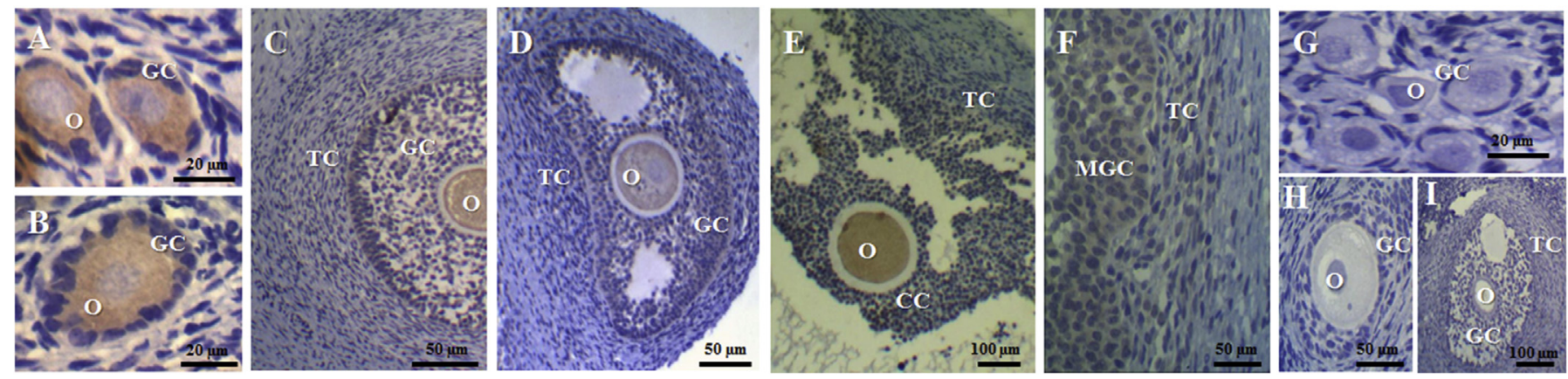

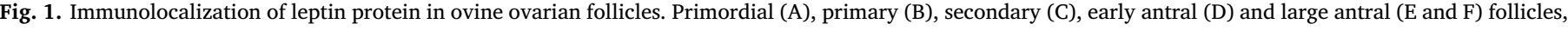

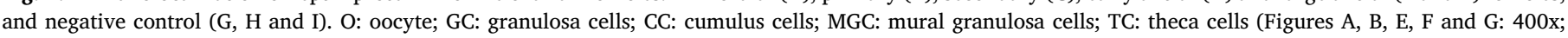
Figures C, D, H and I: 100x).

(Nikon) at 100x magnification. Atretic follicles were those showing darkness of the oocytes and the surrounding granulosa cells, misshapen oocytes, rupture of the basement membrane and/or oocyte extrusion. The following characteristics were analyzed in the morphologically normal follicles: (i) antral cavity formation, defined as the emergence of a visible translucent cavity within the granulosa cell layers, (ii) the diameter of healthy follicles, measured from the basement membrane, which included two perpendicular measurements of each follicle, and (iii) the daily growth rate, calculated as the normal follicle final diameter subtracted from its diameter on day 0 , divided by the number of culture days (18 days).

After 18 days of culture, all healthy follicles were carefully and mechanically opened with $26 \mathrm{G}$ needles under a stereomicroscope (Nikon) for oocyte recovery. The percentage of fully grown oocytes, i.e., oocyte $\geq 110 \mu \mathrm{m}$, was calculated as the number of acceptable quality oocytes $(\geq 110 \mu \mathrm{m})$ recovered out of the total number of cultured follicles (x 100). Furthermore, healthy oocytes were evaluated for intracellular glutathione (GSH) levels and mitochondrial activity.

\subsection{Measurement of GSH levels and metabolically active mitochondria}

After culture, the oocytes were recovered and intracellular GSH levels and mitochondrial activity were measured as previously described (Lins et al., 2017). Briefly, 4-chloromethyl-6.8-difluoro-7-hydroxycoumarin (CellTracker Blue; $\mathrm{CMF}_{2} \mathrm{HC}$; Invitrogen, Eugene, Oregon, USA) and MitoTracker Red (MitoTracker Red, CMXRos, Molecular Probes, Melbourne, Victoria, Australia) were used to detect intracellular GSH and mitochondrial activity levels as blue and red fluorescence, respectively. Approximately 21 oocytes for each treatment were incubated in the dark for 30 min in PBS supplemented with $10 \mathrm{mM}$ of CellTracker Blue and $100 \mathrm{nM}$ MitoTracker Red ${ }^{\circ}$ at $39^{\circ} \mathrm{C}$. After incubation, the oocytes were washed with PBS and the fluorescence was observed under an epifluorescence microscope (Nikon) with UV filters ( $370 \mathrm{~nm}$ for GSH and $579 \mathrm{~nm}$ for active mitochondria) at a magnification of 100x. The oocytes were photographed and the digital images were analyzed by using the Image $\mathrm{J}$ software (National Institutes of Health, Bethesda, MD, USA). The fluorescence intensity was expressed as pixel/oocyte.

\subsection{Maturation of ovine oocytes from in vitro cultured secondary follicles}

In vitro maturation (IVM) was performed in oocytes derived from in vitro grown follicles after 18 days of culture in the control medium ( $\alpha$ $\mathrm{MEM}^{+}$) and in the treatment that obtained the highest percentage of fully grown oocytes. For IVM, additional pairs of ovine ovaries $(\mathrm{n}=10$ ovaries) were collected, washed and transported to the laboratory as described above. After 18 days of culture, all oocytes enclosed in healthy follicles were carefully collected with $26-\mathrm{G}$ needles under a stereomicroscope (Nikon). Only oocytes $\geq 110 \mu \mathrm{m}$ in diameter with a homogeneous cytoplasm and surrounded by at least 1 compact layer of cumulus cells were selected for IVM as previously described (Luz et al., 2012; Lunardi et al., 2016). The cumulus-oocyte complexes (COCs) were transferred to drops of $100 \mu \mathrm{L}$ of maturation medium composed of TCM 199 supplemented with $10 \%$ fetal calf serum (FCS), $1 \mu \mathrm{g} / \mathrm{mL}$ follicle stimulating hormone (human recombinant FSHr; Gonal-F; Serono Laboratórios, São Paulo, Brazil) and $1 \mu \mathrm{g} / \mathrm{mL}$ luteinizing hormone (LH; ovine pituitary) under oil, and incubated for $24 \mathrm{~h}$ under $5 \% \mathrm{CO}_{2}$ in the air (Cecconi et al., 1999). Thereafter, the oocytes were incubated in drops of PBS containing $10 \mathrm{mM}$ Hoechst 33342 for $15 \mathrm{~min}$ at room temperature in the dark and visualized using an epifluorescence microscope (Nikon) with UV filter $(483 \mathrm{~nm})$ at a magnification of $100 \mathrm{x}$. The chromatin configuration (blue fluorescence) was analyzed through observation of the intact germinal vesicle (GV), meiotic resumption (including germinal vesicle breakdown [GVBD] or metaphase I [MI]) or nuclear maturation (metaphase II [MII]).

\subsection{Statistical analysis}

Data from normal follicles, antrum formation, and retrieval of fullygrown oocytes after in vitro culture were expressed as percentages and compared by the Chi-squared test. Data from GSH, active mitochondria, diameter and daily growth rates were submitted to the Shapiro-Wilk test to verify normal distribution of residues and homogeneity of variances. Thereafter, Kruskal-Wallis non-parametric test was used for comparisons. When main effects or interactions were significant, means were compared by test Student Newman Keuls. Data from IVM were submitted to the Fischer exact. The results were expressed as the means \pm standard error mean (SEM), and differences were considered significant when $\mathrm{p}<0.05$.

\section{Results}

\subsection{Immunolocalization of leptin and its receptor (LEPR) in ovine ovaries}

Oocytes of primordial (Fig. 1A) and primary (Fig. 1B) follicles showed a moderate reaction for leptin protein, while oocytes of secondary (Fig. 1C), early antral (Fig. 1D), and large antral follicles (Fig. 1E) showed a weak immunostaining. No reaction was observed for leptin protein in granulosa cells of primordial (Fig. 1A) and primary (Fig. 1B) follicles. However, a weak expression was observed in granulosa cells of secondary (Fig. 1C) and early antral (Fig. 1D) follicles, while theca cells did not show any positive immunoreaction in these follicular categories (secondary and early antral follicles). Cumulus, mural granulosa and theca cells of large antral follicles (Fig. 1E and F) showed a weak immunostaining for leptin protein. No staining was observed in the negative control (Fig. 1G, H and I).

Regarding to receptor, immunohistochemical analysis revealed a strong reaction for LEPR protein in oocytes of primordial (Fig. 2A), 

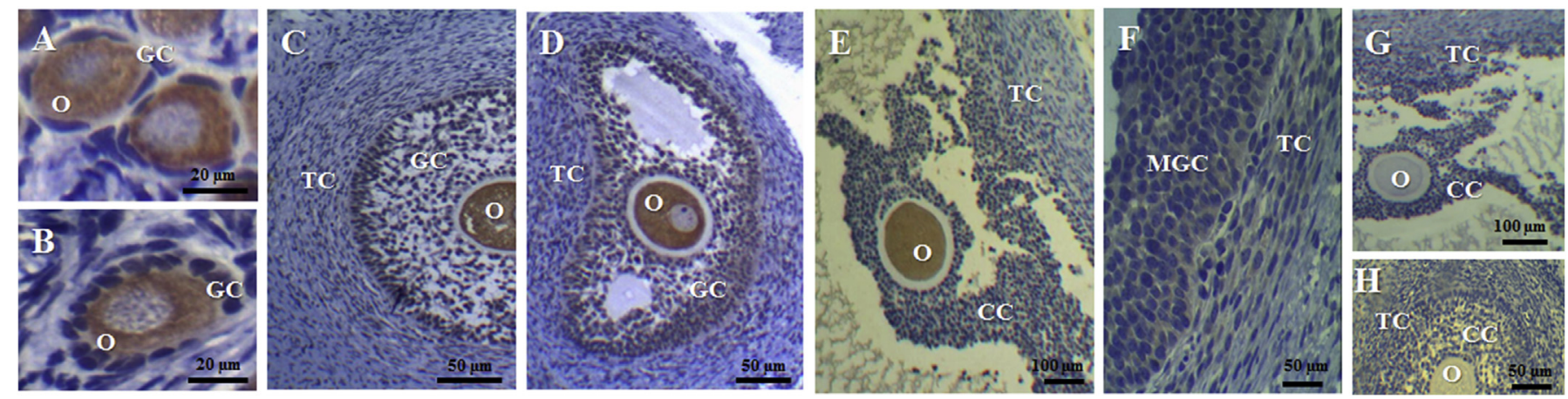

Fig. 2. Immunolocalization of leptin receptor (LEPR) protein in ovine ovarian follicles. Primordial (A), primary (B), secondary (C), early antral (D) and large antral (E and F) follicles, and negative control (G and H). O: oocyte; GC: granulosa cells; CC: cumulus cells; MGC: mural granulosa cells; TC: theca cells (Figures A, B, E, F and G: 400x; Figures C, D and H: 100x).

primary (Fig. 2B), secondary (Fig. 2C), and early antral (Fig. 2D) follicles, whereas a moderate reaction in oocytes of large antral follicles (Fig. 2E). Granulosa cells of primordial follicles (Fig. 2A) did not show a positive reaction for LEPR protein. However, granulosa cells of primary (Fig. 2B) and secondary (Fig. 2C) follicles showed a weak reaction, while granulosa cells of early antral follicles (Fig. 2D) showed a moderate reaction. In addition, a weak reaction was observed in theca cells of secondary and early antral follicles. Cumulus, mural granulosa and theca cells from large antral follicles (Fig. 2E and F) showed a weak reaction for LEPR protein. No staining was observed in the negative control (Fig. 2G and H).

\subsection{Follicular morphology and development after in vitro culture}

Morphologically normal secondary follicles showed centrally located oocytes and normal granulosa cells, which were enclosed by an intact basement membrane (Fig. 3A). At day 6 of culture, antral (Fig. 3B), atretic (Fig. 3C) and extruded (Fig. 3D) follicles were observed. From day 0 to day 18 , there was a reduction $(p<0.05)$ in the percentage of morphologically normal follicles in all treatments (Fig. 4). On day 12 of culture, the percentage of morphologically normal follicles was higher $(\mathrm{p}<0.05)$ in $25 \mathrm{ng} / \mathrm{mL}$ leptin $(71.7 \%$ than other treatments $-55.6 \%$ for $\alpha-\mathrm{MEM}^{+}$and $61.1 \%$ for $10 \mathrm{ng} / \mathrm{mL}$ leptin). However, at the end of culture, no difference ( $p>0.05)$ on the percentage of normal follicles was observed among treatments $(33.3 \%$, $42.6 \%$ and $39.1 \%$ for $\alpha-\mathrm{MEM}^{+}, 10$ and $25 \mathrm{ng} / \mathrm{mL}$ leptin, respectively) (Fig. 4).

The rates of antral cavity formation increased $(\mathrm{p}<0.05)$ in $\alpha$ $\mathrm{MEM}^{+}$and $25 \mathrm{ng} / \mathrm{mL}$ leptin treatments from day 0 to day 6 (Fig. 5). In addition, the medium containing $25 \mathrm{ng} / \mathrm{mL}$ leptin showed higher $(\mathrm{p}<0.05)$ percentage of antral follicles than the other treatments on days $12\left(7.4 \%, 1.9 \%\right.$ and $26.1 \%$ for $\alpha-\mathrm{MEM}^{+}, 10$ and $25 \mathrm{ng} / \mathrm{mL}$ leptin, respectively) and 18 of culture $\left(7.4 \%, 3.7 \%\right.$ and $32.6 \%$ for $\alpha-\mathrm{MEM}^{+}, 10$ and $25 \mathrm{ng} / \mathrm{mL}$ leptin, respectively) (Fig. 5). There were no differences

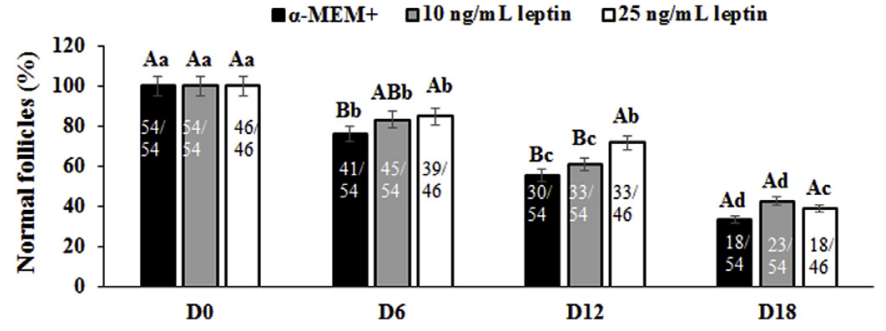

Fig. 4. Percentages of morphologically normal follicles during in vitro culture in control medium $\left(\alpha-\mathrm{MEM}^{+}\right.$) or $\alpha$-MEM ${ }^{+}$containing 10 or $25 \mathrm{ng} / \mathrm{mL}$ leptin. $\left({ }^{\mathrm{a}, \mathrm{b}}\right)$ Different letters denote significant differences among culture periods in the same treatment $(\mathrm{p}<0.05)$. $\left({ }^{\mathrm{A}}, \mathrm{B}\right)$ Different letters denote significant differences among treatments in the same period $(p<0.05)$.

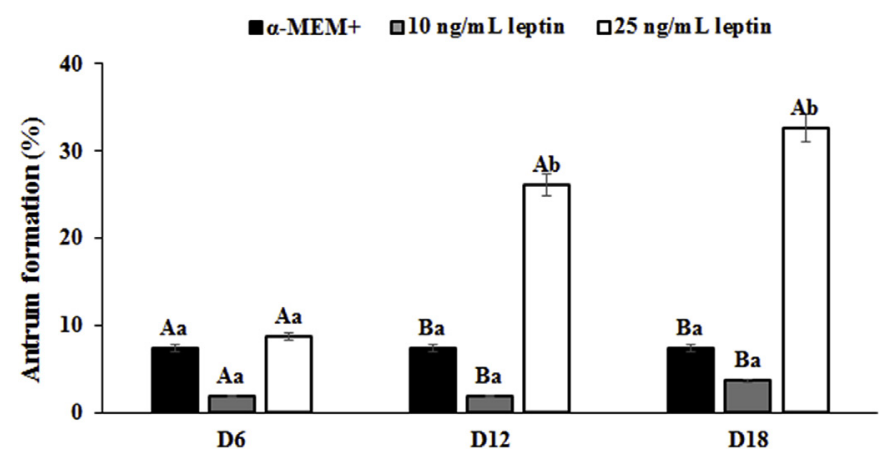

Fig. 5. Percentages of antrum formation during in vitro culture in control medium $\left(\alpha-\mathrm{MEM}^{+}\right)$or $\alpha-\mathrm{MEM}^{+}$containing 10 or $25 \mathrm{ng} / \mathrm{mL}$ leptin. ${ }^{\mathrm{a},}{ }^{\mathrm{b}}$ ) Different letters denote significant differences among culture periods in the same treatment $(\mathrm{p}<0.05)$. $\left({ }^{\mathrm{A}}, \mathrm{B}\right)$ Different letters denote significant differences among treatments in the same period $(\mathrm{p}<0.05)$.
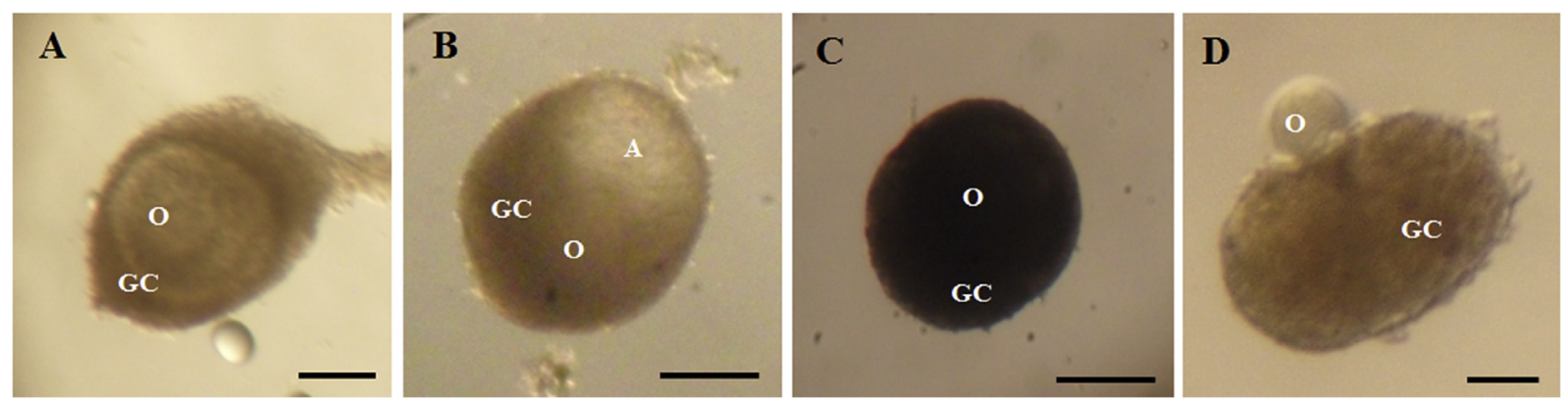

Fig. 3. Morphologically normal secondary follicle at day 0 (A), antral follicle after 6 days of culture in $25 \mathrm{ng} / \mathrm{mL}$ leptin (B), atretic (C), and extruded (D) follicles after 6 days of culture in control medium $\left(\alpha-\mathrm{MEM}^{+}\right)$. O: oocyte; GC: granulosa cell; A: antral cavity. Scale bars: $100 \mu \mathrm{m}(100 \mathrm{x})$. 


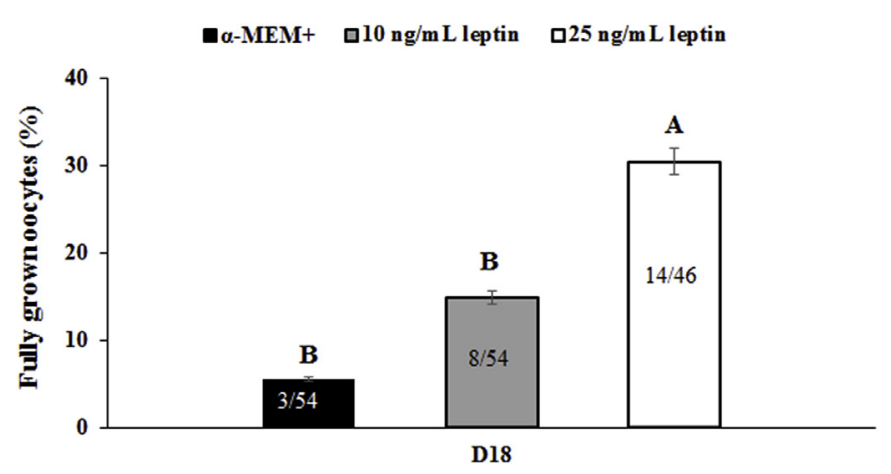

Fig. 6. Percentages of fully grown oocytes after in vitro culture of secondary follicles in control medium $\left(\alpha-\mathrm{MEM}^{+}\right)$or $\alpha-\mathrm{MEM}^{+}$containing 10 or $25 \mathrm{ng} / \mathrm{mL}$ leptin. $\left({ }^{\mathrm{A}, \mathrm{B}}\right)$ Different letters denote significant differences among treatments $(\mathrm{p}<0.05)$.

( $\mathrm{p}>0.05$ ) among treatments regarding to extrusion (no extrusion for $\alpha-\mathrm{MEM}^{+}$and $10 \mathrm{ng} / \mathrm{mL}$, and $8.7 \%$ for $25 \mathrm{ng} / \mathrm{mL}$ leptin), daily growth rate and follicular diameter $(202.2 \mu \mathrm{m}, 215.0 \mu \mathrm{m}$ and $260.0 \mu \mathrm{m}$ for $\alpha$ $\mathrm{MEM}^{+}, 10$ and $25 \mathrm{ng} / \mathrm{mL}$ leptin, respectively). At day 18, treatment containing $25 \mathrm{ng} / \mathrm{mL}$ leptin (30.4\%) significantly increased the percentage of fully grown oocytes (i.e, $\geq 110 \mu \mathrm{m}$ ) compared to the control (5.6\%) and $10 \mathrm{ng} / \mathrm{mL}$ leptin (14.8\%) (Fig. 6).

\subsection{Effects of leptin on intracellular GSH levels and mitochondrial activity}

Regardless of the concentration, leptin significantly increased intracellular GSH levels and mitochondrial activity compared to the control medium $\left(\alpha-\mathrm{MEM}^{+}\right)$after 18 days of culture. Moreover, there was no difference $(\mathrm{p}>0.05)$ between leptin concentrations (10 or
$25 \mathrm{ng} / \mathrm{mL}$ ) (Fig. 7).

\subsection{Chromatin configuration after IVM}

Based on the best results of the percentage of fully grown oocytes, IVM was performed in the oocytes cultured in medium containing $25 \mathrm{ng} / \mathrm{mL}$ leptin, as well as in the control medium $\left(\alpha-\mathrm{MEM}^{+}\right)$. After evaluation of the chromatin configuration, it was possible to observe oocytes in GV (Fig. 8A), GVBD (Fig. 8B), MI (Fig. 8C) and MII (Fig. 8D) in both treatments. However, the concentration of $25 \mathrm{ng} / \mathrm{mL}$ leptin showed a significantly higher percentage of oocytes in MII (33.33\%) than the control medium (5.26\%) (Table 1).

\section{Discussion}

To our knowledge, this study demonstrates for the first time a variable pattern of intensity and distribution of leptin and its receptor expression in sheep ovaries using immunohistochemical analysis. We have also demonstrated that $25 \mathrm{ng} / \mathrm{mL}$ leptin positively influences follicular and oocyte development (higher percentages of antrum formation and fully grown oocyte), increases GSH and active mitochondrial levels, as well as improves oocyte maturation compared to control medium.

In this study, leptin and LEPR proteins were localized in oocytes of all stages of follicle development, which is in agreement to the immunoexpression found in goat oocytes (Batista et al., 2013). Leptin protein was expressed in the granulosa cells of sheep secondary and antral follicles, whereas LEPR was localized in the granulosa cells of primary, secondary and antral follicles. Moreover, leptin protein was found in theca cells of large antral follicles, while its receptor was demonstrated in secondary and antral follicles. Previously, leptin mRNA was expressed in theca cells and both leptin and LEPR mRNA were
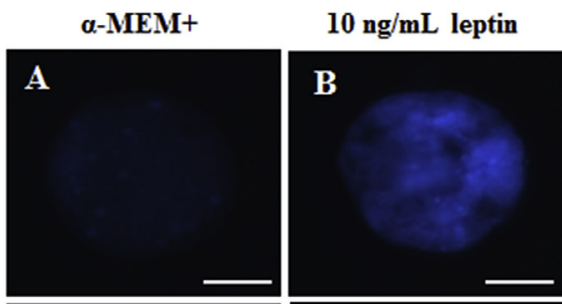

$25 \mathrm{ng} / \mathrm{mL}$ leptin

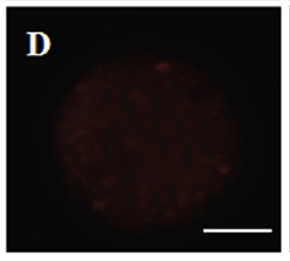

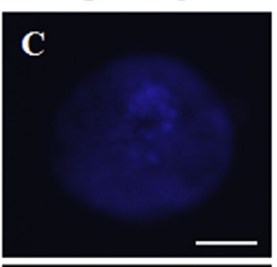

F
E

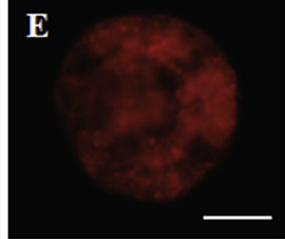

Fig. 7. Detection of intracellular levels of GSH and mitochondrial activity, respectively: oocytes cultured in $\alpha-\mathrm{MEM}^{+}$(A and D) or control medium containing 10 (B and E) or 25 (C and F) ng/mL leptin. Scale bars: $50 \mu \mathrm{m}(100 \mathrm{x})$. Intracellular levels of GSH and active mitochondria in oocytes after in vitro culture $(\mathrm{G})$. ${ }^{\mathrm{A}, \mathrm{B}}$ ) Within each group (GSH or active mitochondria levels), different letters denote significant differences among treatments $(\mathrm{p}<0.05)$.

(G)

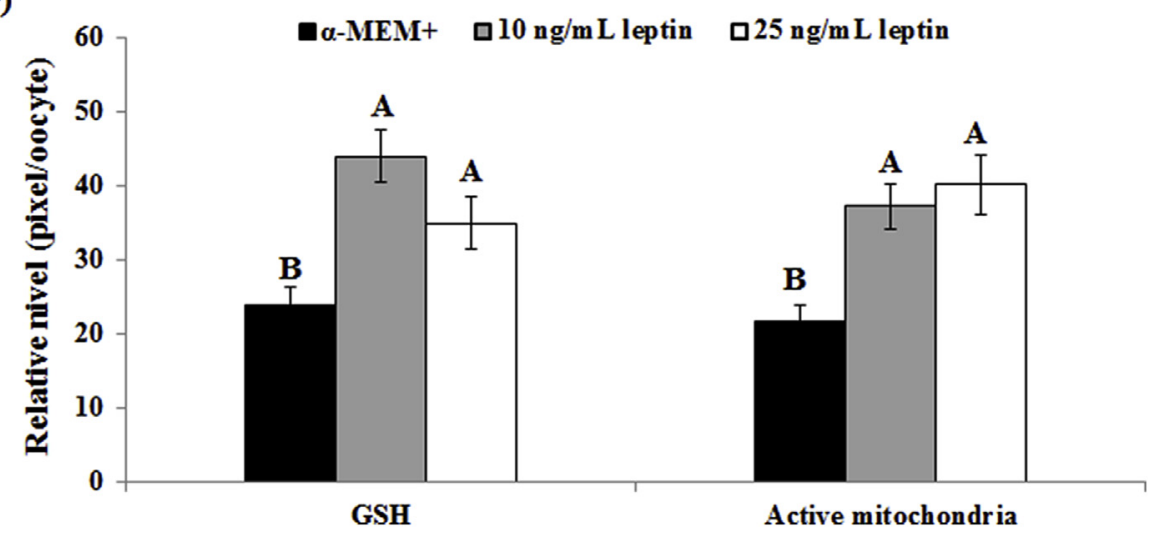



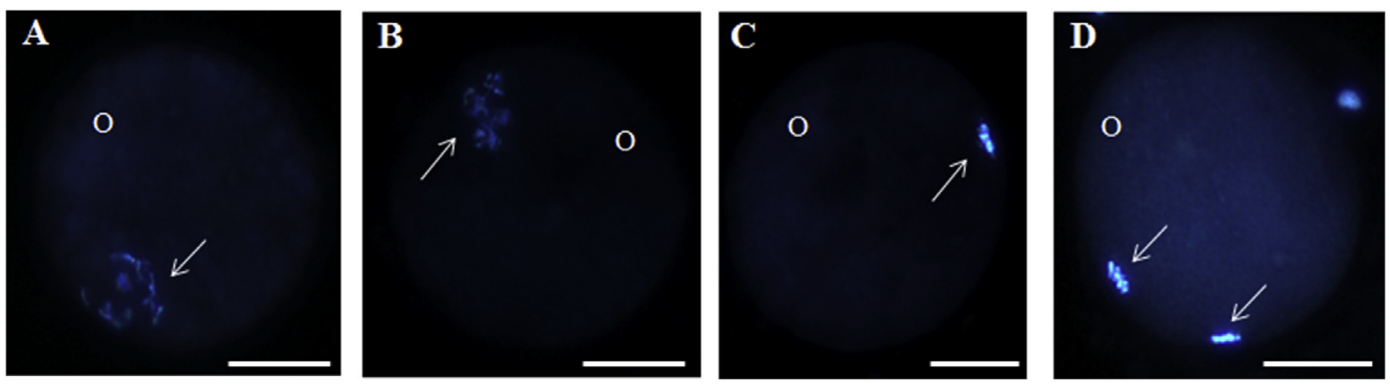

Fig. 8. Epifluorescent photomicrographic images of ovine oocytes from in vitro cultured secondary follicles stained with Hoeschst 33342 after IVM. Oocyte in GV (A), GVBD (B), MI (C) and MII (D) cultured in medium containing $25 \mathrm{ng} / \mathrm{mL}$ leptin. Arrow: nuclear chromatin. Scale bars: $50 \mu \mathrm{m}(100 x)$.

Table 1

Meiotic stages (\%) after in vitro maturation of sheep oocytes from in vitro grown secondary follicles cultured in $\alpha-\mathrm{MEM}^{+}$or medium containing $25 \mathrm{ng} / \mathrm{mL}$ leptin.

\begin{tabular}{lllll}
\hline Treatments & $\%$ GV (n) & $\%$ GVDB (n) & $\%$ MI (n) & $\%$ MII (n) \\
\hline$\alpha-$ MEM $^{+}$ & $47.37(9 / 19)$ & $10.53(2 / 19)$ & $36.84(7 / 19)$ & $5.26(1 / 19)^{\mathrm{B}}$ \\
Leptin 25 ng/mL & $23.8(5 / 21)$ & $9.52(2 / 21)$ & $33.33(7 / 21)$ & $33.33(7 / 21)^{\mathrm{A}}$ \\
\hline
\end{tabular}

$(A, B)$ Different letter superscripts denote significant differences $(p<0.05)$ between treatments.

found in granulosa cells of antral follicles in sheep (Munõz-Gutiérrez et al., 2005) and goat (Batista et al., 2013). Using RT-qPCR, Pisani et al. (2008) detected the long form of LEPR in granulosa cells from ovine antral follicles greater than $2 \mathrm{~mm}$ in diameter. Moreover, leptin and LEPR proteins were reported in granulosa cells during all stages of goat follicular development (Batista et al., 2013). Additionally, leptin immunostaining was also found in granulosa cells, theca interna cells and luteal cells in swine (Phoophitphong et al., 2017). Therefore, the presence of a leptin signaling system in the ovary suggests that it could be involved in the ovarian function in sheep. Moreover, an evaluation of quantitative protein assay would be interesting to elucidate these mechanisms completely.

Although the percentage of morphologically normal follicles was higher in $25 \mathrm{ng} / \mathrm{mL}$ leptin than other treatments at day 12, there was no difference among treatments regarding to follicle survival after 18 days. It is known that early antral follicles become dependent on FSH stimulation (Erickson and Shimasaki, 2001) and this hormone maintained the survival of ovine follicles cultured for 18 days (Barros et al., 2019). Therefore, in the present study, it is possible that the absence of FSH in the base culture medium may have influenced the similar percentage of normal follicles in the different treatments at the end of culture.

Nevertheless, after 18 days of in vitro culture, the concentration of $25 \mathrm{ng} / \mathrm{mL}$ of leptin effectively stimulated more antral cavity formation and oocyte development (higher percentages of fully grown oocytes). It is known that leptin upregulates the in vitro expression of the integral membrane protein aquaporin 9 (AQP9) in human placenta (VilariñoGarcía et al., 2018) and that AQP9 plays an important role in the antrum development of ovine follicles (Sales et al., 2015). Thus, a possible explanation for our results is that $25 \mathrm{ng} / \mathrm{mL}$ leptin may have stimulated the expression of AQP9, increasing antrum formation. Moreover, based on the present immunohistochemistry findings, it is likely that the strong immunoexpression for LEPR (more receptors) found in oocytes of secondary and early antral follicles (and moderate in theca cells of early antral follicles) may have increased follicular responsiveness to this hormone. An increase in concentration of ligand can induce a greater amount of the same type of response by activating more receptors, more cells, or by occupying receptor for a longer time (Gurdon et al., 1998). Thus, these data indicate that an increase in leptin concentration $(25 \mathrm{ng} / \mathrm{mL}$ instead of $10 \mathrm{ng} / \mathrm{mL})$ may be required to promote follicle development (antrum formation) and oocyte growth in vitro for up to 18 days. In contrast, $10 \mathrm{ng} / \mathrm{mL}$ leptin may not be sufficient to support this growth for a period greater than 6 days. These results were different from those reported previously in which $10 \mathrm{ng} / \mathrm{mL}$ leptin exhibited higher growth and antrum formation rates after in vitro culture of ovine secondary follicles (Kamalamma et al., 2016). These differences may be due to mean follicle diameter at the beginning of the culture $(250-270 \mu \mathrm{m}$ in our study x $250-400 \mu \mathrm{m})$, period (18 days in this study x 6 days), and base medium ( $\alpha$-MEM in this study $\mathrm{x}$ TCM 199).

Because mitochondria dysfunction is one of major reason that induces increase of ROS level and compromises oocyte quality (Igosheva et al., 2010; Ou et al., 2012), we further explored GSH level and mitochondrial activity. The GSH serves as an efficient scavenger and plays an important role in maintaining oocytes in a reduced environment, protecting them from oxidative stress. For example, decreased GSH indicated the progression of oxidative stress in mice with insulin resistance (Goud et al., 2008). Moreover, during oocyte maturation, mitochondrial membrane potential is highly important for oocyte quality (Qiang et al., 2007), and is an essential factor in the establishment of oocyte functional competence (Dumollard et al., 2007; Castaneda et al., 2013). In this context, the present study demonstrated that control medium without leptin $(\alpha$-MEM + ) had oocytes with less GSH and active mitochondria levels, which was associated with poor quality oocytes (smaller oocytes than $25 \mathrm{ng} / \mathrm{mL}$ leptin) and consequently affected oocyte maturation $(5.26 \%$ in $\alpha$-MEM $+\mathrm{x} 33.33 \%$ in $25 \mathrm{ng} / \mathrm{mL}$ leptin).

It is important to note that although there were no differences between both concentrations of leptin regarding to GSH or active mitochondria levels, the concentration of $25 \mathrm{ng} / \mathrm{mL}$ of leptin significantly increased the percentage of fully grown oocytes compared to $10 \mathrm{ng} / \mathrm{mL}$. For this reason, IVM was performed only in oocytes that were cultured in medium containing $25 \mathrm{ng} / \mathrm{mL}$ leptin. Our rates of MII oocytes were higher than those previously obtained by Kamalamma et al. (2016) ( $33.33 \% \times 24.06 \%$, respectively). The beneficial effects of leptin on in vitro follicular development, oocyte maturation and embryo production have also been demonstrated in ovine (Kamalamma et al., 2016; Keshrawani et al., 2016) and bubaline (Panda et al., 2017) species. Some studies suggested that leptin and its receptor are directly involved in the regulation of oocyte maturation and embryo development (Kawamura et al., 2002; Craig et al., 2004; Kakisina, 2013). Additionally, it has been suggested that leptin may induce germinal vesicle breakdown in vivo via its action on the theca cells (Ryan et al., 2002) or in vitro by a direct action on the oocyte or indirect on cumulus cells (Paula-Lopes et al., 2007).

In conclusion, leptin and its receptor (LEPR) proteins are expressed in all ovarian follicle stages in sheep. Moreover, the concentration of $25 \mathrm{ng} / \mathrm{mL}$ of leptin improved antrum formation, oocyte growth, GSH levels, mitochondrial activity and oocyte maturation rates compared to control medium. Taken together, these results suggest that leptin has beneficial effects on the development of ovine oocytes by attenuating mitochondrial dysfunction and oxidative stress. 


\section{Conflicts of interest}

None of the authors have any conflict of interest to declare.

\section{Acknowledgments}

This work was supported by FACEPE (Process APQ-0895-5.05/14). T.J.S. Macedo holds a scholarship from the FACEPE. A. Wischral, M.A.A Queiroz, G.G.L. Araújo and M.H.T. Matos are supported by a grant from CNPq. Batista, A.M. is supported by a grant from CAPES.

\section{References}

Arunakumari, G., et al., 2010. Development of morulae from the oocytes of cultured sheep preantral follicles. Theriogenology 74, 884-894.

Barberino, R.S., et al., 2017. Melatonin protects against cisplatin-induced ovarian damage in mice via the MT1 receptor and antioxidant activity. Biol. Reprod. 96, 1244-1255.

Barros, et al., 2019. In vitro survival, growth, and maturation of sheep oocytes from secondary follicles cultured in serum-free conditions: impact of a constant or a sequential medium containing recombinant human FSH. Domest. Anim. Endocrinol. $67,71-79$.

Batista, A., et al., 2013. The expression and localization of leptin and its receptor in goat ovarian follicles. Anim. Reprod. Sci. 141, 142-147.

Bilbao, M.G., et al., 2015. Regulation of the ovarian oxidative status by leptin during the ovulatory process in rats. Reproduction 149, 357-366.

Boelhauve, M., et al., 2005. Maturation of bovine oocytes in the presence of leptin improves development and reduces apoptosis of in vitro-produced blastocysts. Biol. Reprod. 73, 737-744.

Castaneda, C.A., et al., 2013. Circulating concentrations of leptin, ovarian follicle number, and oocyte lipid content and active mitochondria, in Zebucrossbred cows maintained on standard or improvednutrition. Anim. Reprod. Sci. 140, 7-13.

Catteau, A., et al., 2015. Leptin and its potential interest in assisted reproduction cycles. Hum. Reprod. Update 0, 1-22.

Cecconi, S., et al., 1999. In vitro development of sheep preantral follicles. Biol. Reprod. 60, 594-601.

Chappel, S., 2013. The role of mitochondria from mature oocyte to viable blastocyst. Obstet. Gynecol. Int. 1-10.

Chaves, R.N., et al., 2008. Chilling ovarian fragments during transportation improves viability and growth of goat preantral follicles cultured in vitro. Reprod. Fertil. Dev. 20, 640-647.

Chen, Q., et al., 2003. Production of reactive oxygen species by mitochondria. J. Biol. Chem. 278, 36027-36031.

Cioffi, J.A., et al., 1997. The expression of leptin and its receptors in preovulatory human follicles. Mol. Hum. Reprod. 3, 467-472.

Combelles, C.M.H., Gupta, S., Agarwal, A., 2009. Could oxidative stress influence the invitro maturation of oocyte? Reprod. Biomed. Online 18, 864-880.

Craig, J., et al., 2004. Leptin enhances oocyte nuclear and cytoplasmic maturation via the mitogen-activated protein kinase pathway. Endocrinology 145, 5355-5363.

Dumollard, R., et al., 2007. The role of mitochondrial function in the oocyte and embryo. Curr. Top. Dev. Biol. 77, 21-49.

Erickson, G.F., Shimasaki, S., 2001. The physiology of folliculogenesis: the role of novel growth factors. Fertil. Steril. 76, 943-949.

Goud, A.P., et al., 2008. Reactive oxygen species and oocyte aging: role of superoxide, hydrogen peroxide, and hypochlorous acid. Free Radic. Biol. Med. 44, 1295-1304.

Guerin, P., El Mouatassim, S., Menezo, Y., 2001. Oxidative stress and protection against reactive oxygen species in the pre-implantation embryo and its surroundings. Hum. Reprod. Update 7, 175-189.

Gurdon, J.B., et al., 1998. Cells' perception of position in a concentration gradient. Cell 95, 159-162.

Igosheva, N., et al., 2010. Maternal diet-induced obesity alters mitochondrial activity and redox status in mouse oocytes and zygotes. PLoS One 5, e10074. https://doi.org/10. 1371/journal.pone.0010074.

Jin, Y.-X., et al., 2009. Leptin accelerates pronuclear formation following intracytoplasmic sperm injection of porcine oocytes: possible role for MAP kinase inactivation. Anim. Reprod. Sci. 115, 137-148.

Kakisina, P., 2013. The effect of leptin in increasing the quality of goat oocyte maturation in vitro. J. Appl. Environ. Biol. Sci. 3, 10-15.
Kamalamma, P., 2016. Effect of leptin on in vitro development of ovine preantral ovarian follicles. Theriogenology 85, 224-229.

Kawamura, K., et al., 2002. Leptin promotes the development of mouse preimplantation embryos in vitro. Endocrinology 143, 1922-1931.

Keshrawani, S., et al., 2016. Supplementation of leptin on in vitro maturation of sheep oocytes. Asian J. Anim. Vet. Adv. 11, 629-636 2016.

Khaki, A., et al., 2014. Effect of leptin on in vitro nuclear maturation and apoptosis of buffalo (Bubalus bubalis) oocyte. Int. J. Fertil. Steril. 8, 43-50.

Lins, T.L.B.G., et al., 2017. Rutin can replace the use of three other antioxidants in the culture medium, maintaining the viability of sheep isolated secondary follicles. Theriogenology 89, 263-270.

Lunardi, F.O., et al., 2016. Ovine secondary follicles vitrified out the ovarian tissue grow and develop in vitro better than those vitrified into the ovarian fragments. Theriogenology 85, 1203-1210.

Luz, V.B., et al., 2012. Eight-cell parthenotes originated from in vitro grown sheep preantral follicles. Reprod. Sci. 19, 1219-1225.

Macedo, T.J.S., et al., 2017. Resveratrol has dose-dependent effects on DNA fragmentation and mitochondrial activity of ovine secondary follicles cultured in vitro. Zygote 25, 434-442.

Matsuoka, T., 1999. Tyrosine phosphorylation of STAT3 by leptin through leptin receptor in mouse metaphase 2 stage oocyte. Biochem. Biophys. Res. Commun. 256, 480-484.

Munõz-Gutiérrez, M., et al., 2005. The ovarian expression of mRNAs for aromatase, IGF-I receptor, IGF-binding protein-2, -4 and -5 , leptin and leptin receptor in cycling ewes after three days of leptin infusion. Reproduction 130, 869-881.

Niu, et al., 2017. C-Phycocyanin protects against mitochondrial dysfunction and oxidative stress in parthenogenetic porcine embryos. Sci. Rep. 7, 16992.

Ou, X.-H., et al., 2012. Maternal insulin resistence causes oxidative stress and mitochondrial dysfunction in mouse oocytes. Hum. Reprod. 27, 2130-2145.

Panda, B.S.K., et al., 2017. Leptin supplementation in vitro improved developmental competence of buffalo oocytes and embryos. Theriogenology 98, 116-122.

Paula-Lopes, F.F., et al., 2007. Leptin promotes meiotic progression and developmental capacity of bovine oocytes via cumulus cell-indipendent and dipendent mechanisms. Biol. Reprod. 76, 532-541.

Pisani, L.F., et al., 2008. Effects of pre-mating nutrition on mRNA levels of developmentally relevant genes in sheep oocytes and granulosa cells. Reproduction 136, 303-312.

Phoophitphong, D., et al., 2017. Leptin immunohistochemical staining in the porcine ovary. Anat. Histol. Embryol. 46, 334-341.

Qiang, W., et al., 2007. Aging impairs insulin-stimulated glucose uptake in rat skeletal muscle via suppressing AMPKalpha. Exp. Mol. Med. 39, 535-543.

Ramalho-Santos, J., et al., 2009. Mitochondrial functionality in reproduction: from gonads and gametes to embryos and embryonic stem cells. Hum. Reprod. Update 15, $553-572$.

Ryan, N.K., et al., 2002. Expression of leptin and its receptor in the murine ovary: possible role in the regulation of oocyte maturation. Biol. Reprod. 66, 1548-1554.

Sales, A.D., et al., 2015. Steady-state level of messenger RNA and immunolocalization of aquaporins 3,7 , and 9 during in vitro growth of ovine preantral follicles. Theriogenology 84, 1-10.

Santos, L.P., et al., 2014. Protein localization of epidermal growth factor in sheep ovaries and improvement of follicle survival and antrum formation in vitro. Reprod. Domest. Anim. 49, 783-789.

Sheykhani, H.R.S., et al., 2016. Protective effect of leptin on induced apoptosis with trichostatin A on buffalo oocytes. Vet. Res. Forum 7, 99-104.

Silva, J.R.V., et al., 2004. Gene expression and protein localisation for activin-A, follistatin and activin receptors in goat ovaries. J. Endocrinol. 183, 405-415.

Taheri, S.J., Parham, A., 2016. Sheep oocyte expresses leptin and functional leptin receptor mRNA. Asian Pac. J. Reprod. 5, 395-399.

Tartaglia, L.A., et al., 1995. Identification and expression cloning of a leptin receptor. OBR. Cell. 83, 1263-1271.

Tsai, M., et al., 2012. Stimulation of leptin secretion by insulin. Indian J. Endocrinol. Metabol. 16, S543-S548.

Van Blerkom, J., 2004. Mitochondria in human oogenesis and preimplantation embryogenesis: engines of metabolism, ionic regulation and developmental competence. Reproduction 128, 269-280.

Vilariño-García, T., et al., 2018. Leptin upregulates aquaporin 9 expression in human placenta in vitro. Gynecol. Endocrinol. 34, 175-177.

Yu, S., et al., 2014. Protective effect of quercetin on the development of preimplantation mouse embryos against hydrogen peroxide-induced oxidative injury. PLoS One 9 , e89520.

Zhang, Y., et al., 1994. Positional cloning of the mouse obese gene and its human homologue. Nature 372, 425-432. 